\title{
Effect of mechanical surface treatment on the fracture resistance and interfacial bonding failure of Y-TZP zirconia
}

\author{
Yang-Jin Yi* \\ Department of Prosthodontics, Section of Dentistry, Seoul National University Bundang Hospital, Seongnam, Republic of Korea
}

\begin{abstract}
Purpose: Surface damage and bonding strength difference after micromechanical treatment of zirconia surface are to be studied yet. The aim of this study was to evaluate the difference of fracture resistance and bonding strength between more surfacedamaged group from higher air-blasting particle size and pressure, and less damaged group. Materials and Methods: Disk shape zirconia (LAVA ${ }^{\mathrm{TM}}$ ) was sintered and air-blasted with $30 \mu \mathrm{m}$ particle size (Cojet), under 2.8 bar for 15 seconds, $110 \mu \mathrm{m}$ particle size (Rocatec), under 2.8 bar for 15 seconds, and $110 \mu \mathrm{m}$ particle size (Rocatec), under 3.8 bar for 30 seconds respectively. Biaxial flexure test and bonding failure load test were performed serially ( $n=10$ per group). For bonding test, specimens were bonded on the base material having similar modulus of elasticity of dentin with $200 \mu \mathrm{m}$-thick resin cement for tension of surface damage. Failure load of bonding was detected with acoustic emission (AE) sensor. Results: There were no significant differences both in the biaxial flexure test and bonding failure load test between groups $(P>0.05)$. Sub-surface cracks were all radial cracks except for two specimens. Conclusion: Within the limitations of no aging under monotonic load test, surface damage from higher air-blasting particle size and pressure was not significant. Evaluations of failure load with bonded zirconia disks was clinically relevant modality for surface damage and bonding strength, simultaneously. (J Dent Rehabil Appl Sci 2014;30(2):102-11)
\end{abstract}

Key words: acoustic emission; air abrasion; biaxial flexure; bonding; strength; zirconia

\begin{abstract}
서론
지르코니아는 강한 물성과 저렴한 비용을 강점으로 CAD-CAM 기술의 발전과 함께 금 주조수복물의 자리 를 빠르게 대체하고 있다. 통상 세라믹은 접착 강도와 파 절 강도를 동시에 높이기 위해 표면처리 후 레진 시멘 트를 사용하게 되는데 주로 사용하는 표면처리 방법으 로 산부식(etching)이나 샌드블라스팅을 들 수 있다. ${ }^{1}$ 지 르코니아의 경우 강한 물성으로 인해 일반적인 합착재 를 사용해도 되므로 다른 세라믹 재료에 비해 시멘트 선 택의 폭이 크다고 할 수 있다. 반면, 실리카 성분이 없는 polycrystal의 특성상 다른 세라믹과는 달리 산부식이 불
\end{abstract}

*Correspondence to: Yang-Jin Yi, DDS, MSD, PhD Department of Prosthodontics, Seoul National University Bundang Hospital, 300 Gumi-dong, Bundang-gu, Seongnam, 463-707, Republic of Korea Tel: +82-31-787-7546, Fax: +82-31-787-4068, E-mail: navydent@snubh.org Received: April 29, 2014/Last Revision: May 10, 2014/Accepted: May 17, 2014
가능한 데다가 레진 시멘트를 쓰는 경우에도 접착력이 약한 점이 지적되고 있다. 실제로 임상에서는 지르코니 아 크라운의 탈락(decementation)에 대한 다양한 실패가 관찰되고 있으며 ${ }^{2}$ 대상 연구 16 개중 7 개의 논문에서 지 르코니아 치관의 탈락이 있었다는 보고가 있다. ${ }^{3}$ 따라서 지르코니아 수복물의 경우 접착에 대한 임상가들의 각별 한 이해가 필요하다.

$$
\text { 지르코니아는 CAD-CAM으로 제작되므로 기계가공 }
$$
(machining)에 의한 표면 손상에 의해 강도가 급격히 약 해지는 시효처리(aging) 효과가 나타날 우려가 있다. ${ }^{4}$ 또 한 가공 후의 비교적 매끄러운 표면으로는 접착력이 약 해지므로 표면처리가 반드시 필요하다. 강한 치아 접착

Copyright@ 2014 The Korean Academy of Stomatognathic Function and Occlusion. (c) It is identical to Creative Commons Non-Commercial License. 
을 위한 지르코니아 표면의 처리법은 7 가지 정도로 분 류되고 있다 ${ }^{5}$ : 제작 상태 그대로(as-produced), 거칠게 (grinding/polishing), 에어블라스팅(airborne particle abrasion), 표면 코팅(surface coating), 레이저 처리(laser treatment), 산 처리(acid treatment)와 프라이머 도포 (primer treatment). 또한 각각의 표면처리를 좀 더 세분 화하여 tribochemical silicone dioxide (silica) coating, silanization, MDP포함 primer처리, plasma spraying, selective infiltration etching (SIE), zirconia ceramic powder coating, nanostructure alumina coating이 시도 되고 있다. 이중 지르코니아의 접착을 화학적으로 강화 하기 위한 방법으로 여러 가지 monomer성분이 든 접착 제가 시도되고 있으며 ${ }^{6}$ 특히 $\mathrm{MDP}$ 를 함유한 시멘트에 대한 관심이 커지고 있다. ${ }^{6-8}$ 또한 MDP를 함유한 primer 를 중심으로 ${ }^{811}$ 화학적 표면처리를 통한 접착력 강화에 대한 연구도 활발히 진행되고 있다. ${ }^{12,13}$ 그러나 기계적인 처리가 없이 시행된 화학적 표면처리 단독의 효과는 특 히 시효처리 후 일관된 한계를 보였기 때문에 최근의 연 구에서는 기계적 처리를 기본으로 하고 화학적 표면 처 리를 차례로 시행한 지르코니아의 접착 강도만이 신뢰 할만하다고 정리되고 있다. ${ }^{57,10,14-17}$

흔히 샌드블라스팅으로 불리는 airborne particle abrasion (air-blasting)은 사용이 간편하며 air blasting에 의해 tetragonal phase에서 monoclinic phase로 변하며 발생하는 표면 압축으로 균열이 진행하지 못한다는 상 변이 강화(transformation toughening) 효과가 주목 받 았다. ${ }^{18}$ 그러나 다른 세라믹과 마찬가지로 지르코니아도 air-blasting에 의해 표면 손상을 받으면 subcritical crack growth를 유발할 수 있다는 우려가 계속 제기되고 있 다. ${ }^{719-20}$ 특히 많은 연구에서 일정 크기 이상의 particle 을 사용하는 것에 대한 위험을 경고하고 있다. 몇몇 접 착력 평가 실험에서 샌드블라스팅시 $50 \mu \mathrm{m}$ particle과 $110 \mu \mathrm{m}$ particle의 크기 차이가 접착력 측면에서는 유의 한 차이를 보이지 않는다고 나타났다. ${ }^{7,21-23}$ 반면, $50 \mu \mathrm{m}$ particle에 비해 $120 \mu \mathrm{m}$ particle 처리 시편에서 flexure test 강도가 약화되었다는 연구 ${ }^{19}$ 는 접착력은 같으면 서 파절 가능성은 큰 particle size를 표면처리에 굳이 사용할 필요가 없다는 근거가 될 수 있다. 그러나 작은 particle size $\left(50 \mu \mathrm{m}\right.$ particle)에서도 Zhang 등 ${ }^{24}$ 이 2004 년 지르코니아의 강도 저하 효과를 보고한 바 있으므로 particle size에 대한 파절 관점의 연구가 여전히 필요하 다 하겠다.
이제까지 지르코니아 표면 처리 후의 기계적 강도는 flexure test를 통해 평가되었고, 지르코니아와 레진 시멘 트의 접착력 평가는 유한요소분석(FEM)이나 ${ }^{25}$ 표면 접 촉각 ${ }^{13}$ 을 통한 예측이 시도되고 있으나 대부분의 실험에 서 (micro) shear 또는 (micro) tensile test를 중심으로 하 는 in vitro test를 사용하고 있다. 그러나 막상 구강 내에 서는 crown 내면의 시멘트 계면에 압축력(compressive stress)과 전단력(shear stress)이 걸리게 되므로 접착이 된 지르코니아에 저작력이 가해지는 환경이 시멘트 평 가에 필수적이라고 볼 수 있다. ${ }^{26}$ 또한 접착된 계면의 파 절 시점을 알기 위한 시도로 흔히 plotter에 의한 하중변 화나 위치변화 측정이 사용되고 있으나 구강 내의 실패 는 거의 세라믹-시멘트 계면에서 발생하는 radial crack 이 진행하는 것이므로 ${ }^{27}$ 디멘젼의 변화가 거의 없는 초 기 crack을 찾아내기 위한 방법으로는 적절하지 못하다. 따라서 저작력에 의해 발생하는 균열의 관점에서 접착 된 지르코니아 계면의 실패 시점을 정확히 측정하는 파 절저항 연구가 필요하다고 생각된다.

이 실험의 목적은 clinical relevance를 재현한 접착 환 경하에서 지르코니아의 파절 시작시점을 정확히 측정하 여 particle size, 분사 압력과 시간을 다르게 시행하여 거 칠고 손상 받은 표면이 지르코니아 계면 접착강도에 어 떤 영향을 미칠 것인가를 알아보는 것이다. 이를 위하여 각기 다른 기계적 표면처리를 한 지르코니아를 상아질 과 유사한 탄성계수를 가진 베이스에 접착하고 압축 하 중시 발생하는 radial crack을 음향방출(AE) sensor로 찾 아 실패하중을 측정하였으며, 이를 이축 굽힘 하중 실험 결과와 비교하였다.

\section{연구 재료 및 방법}

Y-TZP인 LAVA ${ }^{\mathrm{TM}}$ (3M ESPE, Seefeld, Germany)를 실험 재료로 사용하였다. 반소결된 약 $24.5 \mathrm{~mm}$ 직경의 원통형 시편을 프레임에서 분리하였다. Diamond saw (Isomet 1000, Buehler Ltd., Lake Bluff, IL, USA)를 사 용하여 $1.1-1.2 \mathrm{~mm}$ 의 균일한 두께로 블록을 차례로 잘 라 디스크 형태의 시편을 얻었다. 모든 시편은 $1,500^{\circ} \mathrm{C}$ 에서 11 시간 최종 소결하였다.

소결한 시편은 주수하에 하중을 가하며 회전연삭기로 \#800의 거칠기까지 차례로 연마하였으며 반대편은 평 행을 유지하며 \#320까지 $0.52 \pm 0.01 \mathrm{~mm}$ 의 균일한 두 께로 연마하였다. 연마가 완료된 시편은 연삭 도중 시편 
에 발생한 stress를 없애기 위해 $900^{\circ} \mathrm{C}$ 에서 1 분간 열처 리하였다. ${ }^{28}$ 완성된 시편은 군 당 10 개씩 임의로 나누어 30 개는 2 축 굽힘하중 실험에, 30 개는 접착 실험에 사용 하였다.

\section{1. 이축 굽힘하중 실험 (Fig. 1)}

실험군은 각각 $30 \mathrm{~mm}$ particle tribochemical coating (Cojet $^{\mathrm{TM}}$, 3M ESPE, St. Paul, MN, USA) 15초 분 사군(315), $110 \mathrm{~mm}$ particle tribochemical coating (Rocatect $^{\mathrm{TM}}$ Plus, 3M ESPE) 15초 분사군(1115), 110 $\mathrm{mm}$ particle tribochemical coating (Rocatect ${ }^{\mathrm{TM}}$ Plus) 30 초 분사군(1130)으로 나눠 처리했다. 315 군과 1115 군 은 $1 \mathrm{~cm}$ 거리에서 $2.8 \mathrm{bar}$ 의 압력으로 회전하며 균일하 게 air-blasting 하였으며 1130 군은 $3.8 \mathrm{bar}$ 의 상대적으 로 더 높은 압력으로 시행하였다. air-blasting 후 초음파 세척기에서 1 분간 모든 시편을 세척하고 건조한 후 이 축 굽힘하중 실험을 시행하였다. 다목적 하중시험기로 $0.5 \mathrm{~mm} / \mathrm{min}$ 의 crosshead speed 로 파절시까지 압축 하 중을 가하였다. 스테인레스 피스톤의 지름은 $1.6 \mathrm{~mm}$, support circle의 반지름은 $5 \mathrm{~mm}$ 였으며 시편의 반지름 은 측정 후 약 $9.7 \mathrm{~mm}$ 로 계산하였다. Poisson's ratio는 문헌을 참고하여 0.25 로 설정하였다.

이축 굽힘하중 실험의 실패 강도 계산식은 다음과 같 다(ASTM F394-78).

$\mathrm{S}=-0.2387 \mathrm{P}(\mathrm{X}-\mathrm{Y}) / \mathrm{d}^{2}$

$\mathrm{S}=$ Maximum Flexure Strength, $(\mathrm{MPa})$

$\mathrm{P}=$ Total load before causing fracture, $(\mathrm{N})$

$$
\begin{aligned}
& \mathrm{X}=(1+v) \ln (\mathrm{B} / \mathrm{C})^{2}+[(1-v) / 2](\mathrm{B} / \mathrm{C})^{2} \\
& \mathrm{Y}=(1+v)\left[1+\ln (\mathrm{A} / \mathrm{C})^{2}\right]+(1-v)(\mathrm{A} / \mathrm{C})^{2} \\
& \mathrm{~d}=\text { Thickness of the specimen at fracture origin, }(\mathrm{mm})
\end{aligned}
$$

$v=$ Poisson's ratio

$\mathrm{A}=$ Radius of support circle, $(\mathrm{mm})$

$\mathrm{B}=$ Radius of loaded area, $(\mathrm{mm})$

$\mathrm{C}=$ Radius of the specimen, $(\mathrm{mm})$

\section{2. 접착 파절 실험 (Fig. 1)}

다른 표면 처리 조건은 이축 굽힘하중 실험과 같다. $110 \mu \mathrm{m}$ 샌드블라스팅군의 두께 소실량은 예비실험을 통 해 $35 \mu \mathrm{m}$ 처리군에 비해 $10-30 \mathrm{~mm}$ 에 그침을 확인하였 다. 최종 두께는 $0.52 \pm 0.01 \mathrm{~mm}$ (315), $0.52 \pm 0.01 \mathrm{~mm}$ (1115), $0.51 \pm 0.01 \mathrm{~mm}$ (1130)였다. Air-blasting 후 초음 파 세척기에서 1 분간 시편을 세척한 후 건조하였다. 표 면을 Metal/zirconia primer (Ivoclar-Vivadent, Schaan, Liechtenstein)로 충분히 도포하고 2분간 기다린 후 바 람을 불어 건조시켰다. 상아질과 유사한 탄성계수를 가진 베이스는 woven glass fiber epoxy (NEMA G10, International Paper, Hampton, SC, USA)로 제작하였다. 지름 $20 \mathrm{~mm}$ 의 G10 기둥을 두께 $5 \mathrm{~mm}$ 가 되도록 평행하 게 절단하고 접착면을 \#600의 거칠기가 되도록 연마한 후 에탄올로 표면을 닦아내었다. 완성된 지르코니아 시편 은 $200 \mathrm{~mm}$ 의 시멘트 두께가 되도록 마이크로미터를 조 정하여 베이스에 접착하고 30 초간 광중합 하였다. 시편 의 접착에는 Rely-X Unicem (3M ESPE)을 사용하였다. 접착된 시편은 증류수에 담가 72 시간 상온에서 보관하였다.
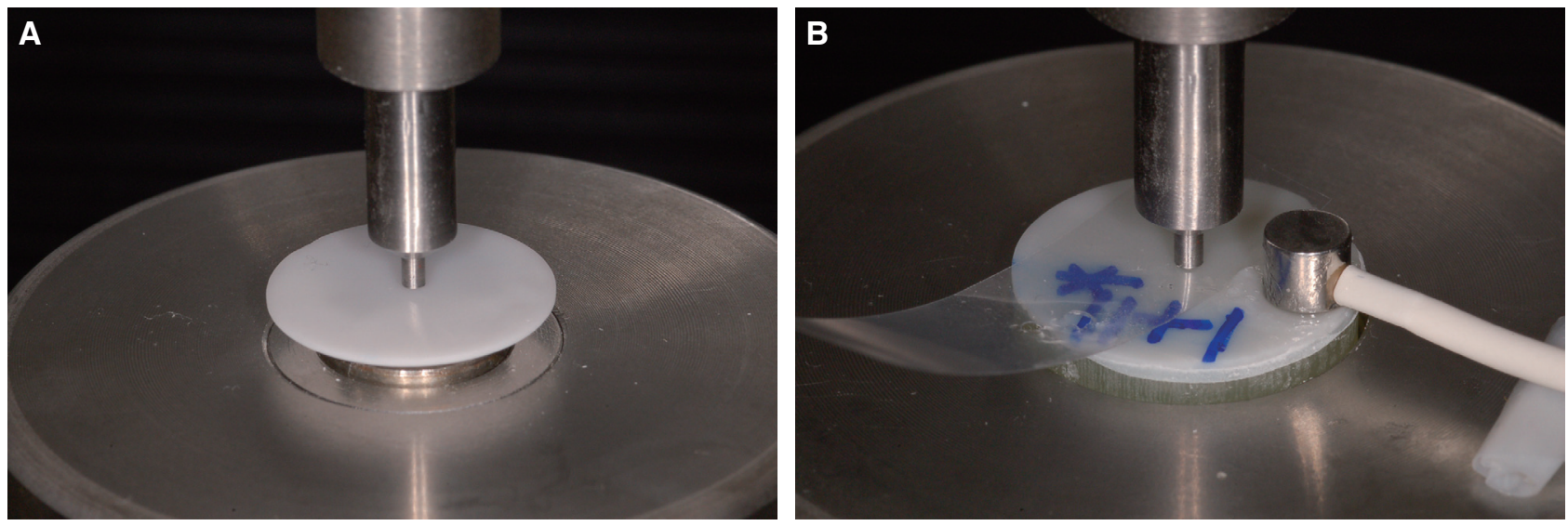

Fig. 1. (A) Biaxial flexure test, (B) Bonded failure test. An AE sensor was attached onto the bonded zirconia specimen. 
지르코니아의 시편 중심에서 일정거리를 유지하도 록 주의하면서 AE sensor (Pico, Physical Acoustics Co., Princeton, NJ, USA)를 상부 표면에 실리콘으로 부 착하였다. 다목적 하중시험기(Microload tester, $\mathrm{R} \& \mathrm{~B}$, Daejeon, Korea)에서 지름 $1.6 \mathrm{~mm}$ 의 피스톤으로 0.5 $\mathrm{mm} / \mathrm{min}$ 의 crosshead speed로 압축하중을 가하였다. 하 중을 가하는 동안 발생한 음향은 $40 \mathrm{~dB}$ 로 증폭되어 10 $\mathrm{kHz}-2 \mathrm{MHz}$ 의 band-pass filter를 통과하여 AE signal process unit (mDisp, Physical Acoustics Co.)에 기록되 고 연결된 컴퓨터 소프트웨어로 분석하였다. Threshold 는 $40 \mathrm{~dB}$ 로 조정하였으며 peak amplitude와 energy등의 $\mathrm{AE}$ parameter를 검사하였다.

음향이 방출되면 압축 하중을 가하는 것을 즉시 중단 하고 trans-illumination light로 radial crack의 발생을 살 폈으며 Hertzian cone crack의 발생 여부도 주의하여 살 펴보았다. 실패 하중은 음향 방출 시간과 하중 속도로부 터 계산하였다.

\section{3. 통계 및 Weibull 분석}

측정결과는 Weibull법으로 표면처리 특성에 따른 차 이를 살펴보았다. 얻어진 결과를 가지고 Weibull 분석을
시행하였다. 아래의 공식을 이용하여 Weibull modulus (m)와 characteristic strength $\left(\sigma_{0}\right), 10 \%$ 실패 하중인 B10 strength를 얻었다.

$$
\begin{aligned}
& \operatorname{Pf}=1-\exp \left[-\left(\sigma / \sigma_{0}\right)^{\mathrm{m}}\right] \\
& \ln \{\ln [1 /(1-\mathrm{Pf})]\}=\mathrm{m} \ln \sigma-\mathrm{m} \ln \sigma_{0}
\end{aligned}
$$

Shapiro-Wilk test로 정규성 검사 후 95\% 유의 수준에 서 ANOVA 를 시행하였다.

\section{결과}

이축 굽힘하중 실험의 결과 $30 \mu \mathrm{m}$ particle size, 2.8 bar 15초 분사군(315)과 $110 \mu \mathrm{m}$ particle size, 2.8 bar 15 초 분사군(1115), $110 \mu \mathrm{m}$ particle size, $3.8 \mathrm{bar} 30$ 초 분사 군(1130) 간 파절 강도에 유의성 있는 차이가 발견되지 않았다 $(P=0.211$, Fig. 2). 그러나 particle size가 커지고 압력이 세질수록 평균값과 세라믹 강도의 특성상 더 큰 의미를 가지는 characteristic strength 모두 강도는 점차 감소하는 경향을 보였다(Table 1). Weibull값은 1115군에 서 매우 높았으나 압력과 시간을 더 증가시킨 1130군에 서는 같은 particle size였음에도 가장 낮은 값을 보였다.

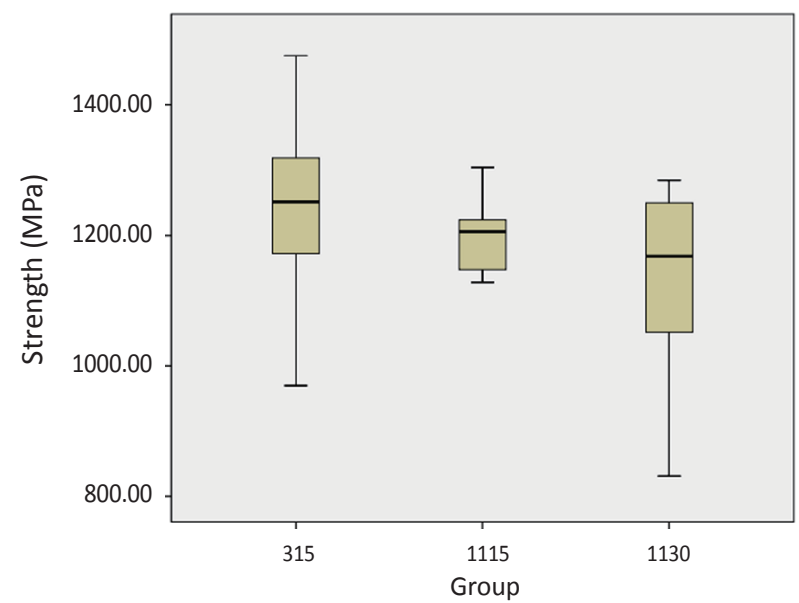

Fig. 2. Fracture strength of biaxial flexure test.

Table 1. Fracture strength, Weibull modulus $(\mathrm{m})$, characteristic strength $(\sigma 0)$, and B10 strength of biaxial flexure test

\begin{tabular}{cllccrr}
\hline Group & $\mathrm{N}$ & Mean $(\mathrm{SD})[\mathrm{MPa}]$ & Grouping $(\alpha=.05)^{*}$ & $\mathrm{~m}$ & $\sigma_{0}[\mathrm{MPa}]$ & $\mathrm{B} 10[\mathrm{MPa}]$ \\
\hline 315 & 10 & $1244.10(141.65)$ & $\mathrm{A}$ & 8.35 & 1309.30 & 993.75 \\
1115 & 10 & $1198.88(53.58)$ & $\mathrm{A}$ & 21.47 & 1225.19 & 1100.59 \\
1130 & 10 & $1130.48(140.57)$ & $\mathrm{A}$ & 7.30 & 1199.90 & 875.30 \\
\hline
\end{tabular}

$\mathrm{SD}$, standard deviation.

* Groups with same letters are not significantly different. 


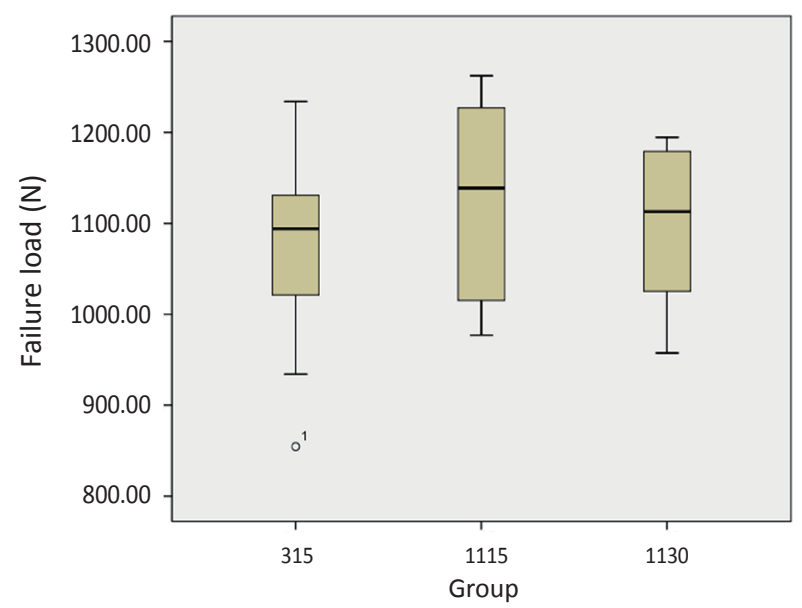

Fig. 3. Failure loads of bonded zirconia specimens.

Table 2. Failure loads, Weibull modulus (m), characteristic strength ( $\sigma 0)$, and B10 strength of bonded zirconia specimens

\begin{tabular}{ccccccc}
\hline Group & $\mathrm{N}$ & Mean $(\mathrm{SD})[\mathrm{N}]$ & Grouping $(\alpha=.05)^{*}$ & $\mathrm{~m}$ & $\sigma 0[\mathrm{MPa}]$ & $\mathrm{B} 10[\mathrm{MPa}]$ \\
\hline 315 & 10 & $1075.73(118.82)$ & $\mathrm{A}$ & 8.65 & 1141.39 & 874.64 \\
1115 & 10 & $1133.37(103.59)$ & $\mathrm{A}$ & 10.52 & 1187.97 & 954.44 \\
1130 & 10 & $1099.46(78.41)$ & $\mathrm{A}$ & 13.56 & 1141.39 & 963.14 \\
\hline
\end{tabular}

SD, standard deviation.

* Groups with same letters are not significantly different.
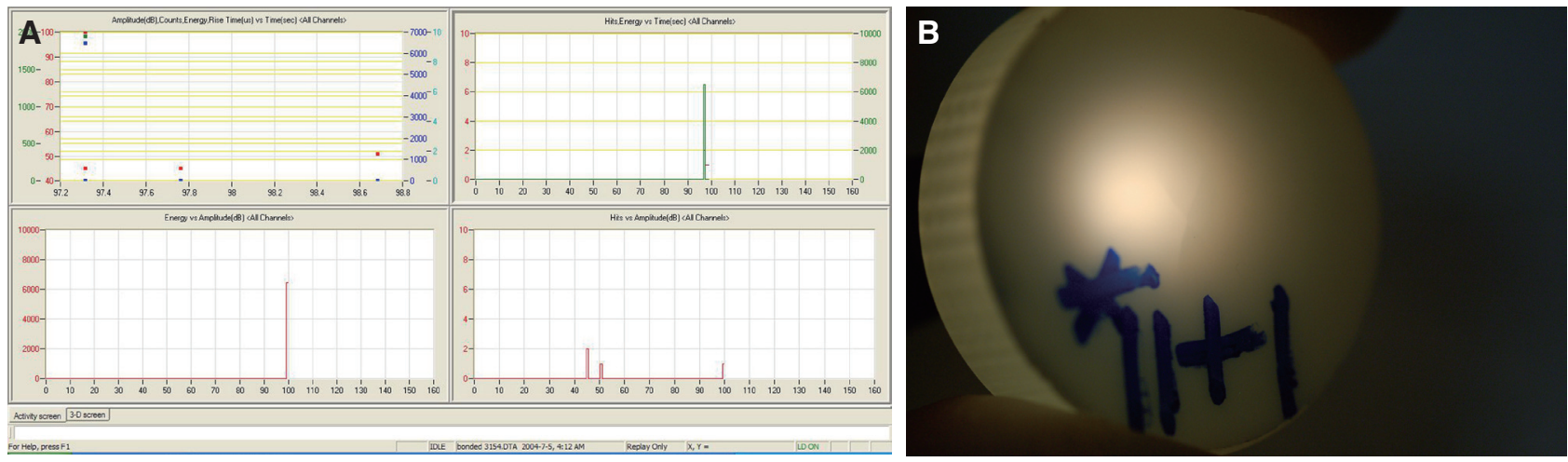

Fig. 4. (A) Diagram of AE signals from a bonded specimen, (B) Trans-illuminated subsurface radial crack.

접착 시편의 파절 하중은 315 군과 1130 군이 비슷한 값을 보였으며 1115 군이 약간 큰 값을 보였지만 세 군 간의 유의한 차이는 없었다 $(P=0.454$, Table 2, Fig. 3). Weibull값은 이축 굽힘하중 실험의 경향과는 달리 315 , 1115,1130 군의 순서로 점차 증가하였다. 접착된 지르코 니아 시편의 실패는 1130 군의 2 개 시편에서 cone crack 을 보인 것을 제외하고는 나머지 모두 radial crack이 발 생되었다(Fig. 4). 음향 방출 amplitude값은 모두 $95 \mathrm{~dB}$ 이상이었다.

\section{고찰}

이 실험은 이전의 실험에서 시도된 것보다 더 큰 분사 압력과 더 긴 시간의 air-blasting으로 표면 손상을 극대 화시킨 군을, 일반적으로 안전하다고 권장되는 한도 내 의 particle size와 분사 압력으로 처리한 군과 비교하여 표면 손상이 지르코니아 강도에 어떻게 영향을 미치는 지 알아보고자 시행되었다.

Ali 등은 15 도와 30 도의 taper로 삭제한 치아에 지르 
코니아 코핑을 레진 시멘트로 접착하고 탈락 하중을 비 교하여 30 도에서 하중이 유의성 있게 작음을 보고하였 다. ${ }^{29}$ 이것은 레진 시멘트의 접착 효과를 의심할 만한 사 항으로 지르코니아는 접착 유지력이 필요한 수복물에 쓸 수 없다고 결론 내린 Ozcan 등 $^{30}$ 의 연구와도 일치한 다. 그러므로 지르코니아에 레진 시멘트를 사용하기 위 해서는 적절한 시멘트 계면의 표면처리가 필요하며 접 착력은 높이면서 crack 발생은 없도록 하는 게 관건이 될 수 있다. 그러나 이제까지 particle size차이에 의한 접 착 효과는 시멘트의 인장/전단력 실험으로 평가되어 왔 으며, particle size차이에 의한 균열 실험은 flexure test 로 시도되는 것이 일반적인 방법이었다. 반면 구강 내에 서는 crown내면에 교합력이 집중되는 환경이므로 시멘 트 접착 효과는 압축력 하에서 평가되어야 하며, 균열 의 진행 여부도 레진 시멘트가 도포된 상태에서 치유효 과를 평가하는 것이 적절하다. 하지만 이런 조건의 실 험은 매우 드물다. ${ }^{24,26}$ 이 실험은 air-blasting시 사용하는 particle size의 크기와 분사 조건이 압축력하의 지르코 니아 접착 강도에 영향을 미치는가, 측정 방법은 합리적 인가 하는 의문에서 시작되었다고 볼 수 있다.

Particle size와 관련된 연구에서 접착력과 관련해서 는 비슷한 결론을 보이고 있다. $\operatorname{Re}$ 등은 $50 \mu \mathrm{m}$ 보다 는 $110 \mu \mathrm{m}$ 군에서 접착력이 최대가 되었다고 보고하 였다. ${ }^{31}$ 그러나 대부분의 연구에서 결론은 particle size 와 bonding strength 간 차이가 없다는 것이다. Chai 등 은 전단력 실험을 통해 $30 \mu \mathrm{m}$ 와 $110 \mu \mathrm{m}$ 의 차이가 없었 다고 하였으며 ${ }^{32}$ Northduft 등도 접착성 모노머가 포함 된 레진 시멘트를 사용한 경우에 같은 결과를 보고한 바 있다. ${ }^{6}$ Monaco 등 ${ }^{21}$, Ozcan 등 ${ }^{22}$, Phark 등 ${ }^{23}$ 은 $50 \mu \mathrm{m}$ 와 $110 \mu \mathrm{m}$ 의 차이가 없었다고 하였고 Gomes 등 은 $50 \mu \mathrm{m}$ 와 $110 \mu \mathrm{m}$ 로 처리한 군 간 비교에서 차이는 오직 시멘 트 종류에서만 발생하였다고 하였다. 분사 조건과 관련 한 연구에서는 분사 압력이 작아도 cleaning 방법이나 ${ }^{33}$ primer, 시멘트에 따라 ${ }^{16}$ 충분히 좋은 결과를 얻을 수 있 음이 보고되었으며 일반적으로 접착력과 관련하여서는 작은 분사 압력은 문제가 되는 것 같지 않다. ${ }^{16,31,33,34}$

반면 파절 관점에서 Wang 등은 $50 \mu \mathrm{m}$ 와 $120 \mu \mathrm{m}$ 로 각각 처리한 시편의 flexure test결과 $120 \mu \mathrm{m}$ 시편의 약 화 효과를 보고하였다. ${ }^{19}$ 앞서의 접착력 결과와 비교하 면 particle size에 따라 접착과 파절 하중간에 표면 처리 효과의 차이가 있을 수 있음을 알 수 있다. 이번 실험의 분사 조건은 이전의 실험에 비해 가장 큰 particle size를
권장되는 분사 압력보다 더 크게 하고 더 긴 시간을 가 하여 이전의 실험조건보다 더 크게 되게 의도하였으나 결과의 차이는 보이지 않았다. Karacoca 등은 $4 \mathrm{bar}+3$ $\mathrm{cm}$ 거리를, ${ }^{20}$ Guess 등은 $5 \mathrm{bar}+0.5 \mathrm{~cm}$ 거리를 분사 조 건으로 설정한 바 있으나 ${ }^{26}$ 분사 시간은 각각 15 초와 5 초에 그친 바 있다.

이 실험에서 표면처리는 기계적으로 particle size 에 차이를 줌과 동시에 Cojet 이나 Rocatec을 이용한 tribochemical coating으로 화학적 도움도 받도록 하였 다. ${ }^{9,17,35}$ 이것은 air-blating particle size는 차이가 나되 군 마다 같은 표면 처리 환경을 제공함과 더불어 최대한 레 진 시멘트의 접착력을 높여 균열 치유 효과가 나타나도 록 함이었다. 이를 위해 air-blasting 후 표면에 Metal/ zirconia primer를 도포하여 레진 시멘트의 접착력 증가 를 고려하였으며 접착성 모노머를 포함한 self-adhesive resin cement 를 사용하였다.

표면 flaw에 의한 파절에 취약한 취성 높은 세라믹 재 료에서 Weibull 분석은 필수적이다. 각각 전체의 $63.2 \%$ 와 $10 \%$ 의 실패를 일으키는 강도인 $\mathrm{s}_{0}, \mathrm{~B} 10$ strength를 분석함으로써 구강 내에서 심각한 문제가 될 수 있는 낮 은 강도에서 파절 되는 표본에 대한 정보가 평균값에 가 려지는 것을 막을 수 있다. Weibull modulus, $\mathrm{m}$ 은 시편 에 발생한 균열의 위치 및 분포를 나타내는 척도이나 air-blasting의 특성상 실험마다 값이 달라지는 면이 있 어 단순 비교는 어렵다. 이번 실험에서는 1130 군에서 biaxial flexure test 보다 접착 후 $\mathrm{m}$ 이 크게 증가하였는데 이전의 flexure test 연구에서 air-blasting후 $\mathrm{m}$ 값이 떨어 졌다고 한 것과는 달랐다. 이것이 거칠기 증가와 레진시 멘트의 강한 결합력으로 인한 균열 치유 효과인지 표면 에 발생한 압축력의 효과인지는 확실하지 않다. 그러나 biaxial flexure test에서 표면 압축력이 발휘되지 않았으 므로 레진 시멘트의 균열 치유 효과로 생각되며 이에 대 한 보충 실험이 필요하다.

본 실험에서는 상아질과 유사한 탄성계수를 가진 베 이스를 사용하고 CAD-CAM 제작 과정 중 발생하는 교 합면 측 시멘트 gap을 문헌에 근거하여 두껍게 설정, 실 제 임상에서 일어날 수 있는 조건을 최대한 구현하였다. 일반적으로 CAD-CAM 방법으로 제작된 crown의 변연 은 임상적으로 적절하나 교합면 등에서는 매우 큰 gap 이 발생한다고 알려져 있다. 많은 문헌에서 교합면 측 내면의 시멘트 공간이 $200 \mu \mathrm{m}$ 전후가 됨을 보고하였 다. ${ }^{36,37}$ 시멘트 공간이 늘어날수록 계면에 주응력이 커지 
고 레진시멘트의 경우 중합수축으로 인해 접착력의 효 과가 소실될 수 있다. ${ }^{25,38}$ 본 실험에서 구현한 비교적 두 꺼운 시멘트 두께는 지르코니아-시멘트 계면의 인장력 이 발휘되기 쉬운 환경을 만들어 표면 균열의 진행을 극 대화하려는 의도였다. 결과적으로 시멘트 접착계면에 인장력이 최대한 발생하도록 하여 radial crack 발생에 적절하면서 시편 표면 Hertzian cone crack의 발생은 최 대로 억제된 결과를 얻었다.

Kelly 등은 구강에서 실패한 세라믹 치관을 분석하여 접착 치관의 내면인 시멘트 접착계면에서 발생한 radial crack이 실패 원인이라고 하였다. ${ }^{27}$ Radial crack은 저작 력하에 진행하여 세라믹 수복물이 갑자기 파절하게 된 다. 따라서 세라믹의 실패강도를 측정하려면 임상에서 와 같이 접착된 시편에서 계면의 radial crack발생 시점 을 검증하는 방법이 가장 합리적이라 할 수 있다. 세라 믹 시편의 초기 균열의 발생을 찾기 위해서 여러 가지 방법이 시도되고 있다. 음향방출 신호를 측정하는 $\mathrm{AE}$ (Acoustic Emission) 법은 물질이 변형되거나 파괴될 때 방출되는 에너지에 의한 acoustic pulse를 검출하는 원 리로 보이지 않는 내면의 미세한 결함이나 균열의 진행 을 탐지할 수 있다. ${ }^{39} \mathrm{AE}$ 는 발생한 결함의 크기나 모양, 방향성에 대한 정보를 제공하며 피로에 의해 발생한 매 우 작은 균열까지 검출해낼 수 있을 정도로 민감하여 계 면의 crack 검출에 유용하다. ${ }^{40}$ 이번 실험에서 대부분의 시편에서 radial crack이 발생되었는데 air-blasting후 접 착한 계면에서 radial crack이 발생하였다는 Guess 등의 결과와 일치한다. ${ }^{26}$

시멘트에 대한 수분과 온도 변화에 따른 영향이 균열 전개에 중요한 관건이 될 수 있으며 지르코니아의 저온 열화 현상과 관련하여 중요한 사항이지만 이번 실험에 서는 시효처리에 의한 영향은 검증하지 못하였다. 많은 연구에서 시효 처리 후 시멘트 접착력이 급격히 떨어짐 을 보고한 바 있으므로 본 실험과 같이 표면 손상을 크 게 강조한 시편의 시효 처리 효과에 대한 보충 실험이 필요하다 하겠다. 또한 구강 내에서와 마찬가지로 동하 중 하에서는 파절하중이 훨씬 줄어들므로 미래의 실험 에서는 이런 점들이 고려되어야 한다.

이 실험은 지르코니아의 표면처리 후 파절 강도에 표 면 손상과 접착이 미치는 영향을 실제 구강 내 저작 환 경과 유사한 잘 조절된 측정 방법으로 평가한 점에 의의 가 있다 하겠다.

\section{결론}

오랜 시효 처리 과정 없이 정하중으로 실험한 한계 내 에서, 큰 particle size와 강한 분사 조건에 의해 표면 손 상이 더 컸다고 여겨지는 군과 상대적으로 작은 손상을 받았다고 생각되는 군간의 굽힘하중 강도와 접착 후 파 절 하중은 차이를 보이지 않았다. 표면처리 후 접착 파 절 저항을 보는 방법은 표면 손상과 접착 강도를 동시에 평가할 수 있어서 임상적으로 관련성이 크고 의미 있는 방법이라 여겨진다.

\section{Acknowledgements}

This study was supported by the R\&D fund of Seoul National University Bundang Hospital (No. 11-2008016).

\section{References}

1. Yi YJ, Kelly JR. Failure responses of a dental porcelain having three surface treatments under three stressing conditions. Dent Mater 2011;27:1252-8.

2. Raigrodski AJ, Hillstead MB, Meng GK, Chung $\mathrm{KH}$. Survival and complications of zirconia-based fixed dental prostheses: a systematic review. J Prosthet Dent 2012;107:170-7.

3. Al-Amleh B, Lyons K, Swain M. Clinical trials in zirconia: a systematic review. J Oral Rehabil 2010; 37:641-52.

4. Kim JW, Covel NS, Guess PC, Rekow ED, Zhang Y. Concerns of hydrothermal degradation in CAD/ CAM zirconia. J Dent Res 2010;89:91-5.

5. Papia E, Larsson C, du Toit M, Vult von Steyern P. Bonding between oxide ceramics and adhesive cement systems: a systematic review. J Biomed Mater Res B Appl Biomater 2014;102:395-413.

6. Nothdurft FP, Motter PJ, Pospiech PR. Effect of surface treatment on the initial bond strength of different luting cements to zirconium oxide ceramic. Clin Oral Investig 2009;13:229-35.

7. Gomes AL, Castillo-Oyagüe R, Lynch CD, Montero J, Albaladejo A. Influence of sandblasting granulometry and resin cement composition on microtensile bond strength to zirconia ceramic for 
dental prosthetic frameworks. J Dent 2013;41:3141.

8. Koizumi H, Nakayama D, Komine F, Blatz MB, Matsumura H. Bonding of resin-based luting cements to zirconia with and without the use of ceramic priming agents. J Adhes Dent 2012;14:38592.

9. Inokoshi M, Poitevin A, De Munck J, Minakuchi S, Van Meerbeek B. Bonding effectiveness to different chemically pre-treated dental zirconia. Clin Oral Investig 2013 Nov 27. [Epub ahead of print]

10. Yun JY, Ha SR, Lee JB, Kim SH. Effect of sandblasting and various metal primers on the shear bond strength of resin cement to Y-TZP ceramic. Dent Mater 2010;26:650-8.

11. Foxton RM, Cavalcanti AN, Nakajima M, Pilecki P, Sherriff M, Melo L, Watson TF. Durability of resin cement bond to aluminium oxide and zirconia ceramics after air abrasion and laser treatment. J Prosthodont 2011;20:84-92.

12. Keul C, Liebermann A, Roos M, Uhrenbacher J, Stawarczyk B, Ing D. The effect of ceramic primer on shear bond strength of resin composite cement to zirconia: a function of water storage and thermal cycling. J Am Dent Assoc 2013;144:1261-71.

13. Chen L, Suh BI, Brown D, Chen X. Bonding of primed zirconia ceramics: evidence of chemical bonding and improved bond strengths. Am J Dent 2012;25:103-8.

14. Inokoshi M, De Munck J, Minakuchi S, Van Meerbeek B. Meta-analysis of bonding effectiveness to zirconia ceramics. J Dent Res 2014;93:329-34.

15. Amaral M, Belli R, Cesar PF, Valandro LF, Petschelt A, Lohbauer U. The potential of novel primers and universal adhesives to bond to zirconia. J Dent 2014;42:90-8.

16. Yang B, Barloi A, Kern M. Influence of air-abrasion on zirconia ceramic bonding using an adhesive composite resin. Dent Mater 2010;26:44-50.

17. Qeblawi DM, Muñoz CA, Brewer JD, Monaco EA Jr. The effect of zirconia surface treatment on flexural strength and shear bond strength to a resin cement. J Prosthet Dent 2010;103:210-20.

18. Kosmac T, Oblak C, Jevnikar P, Funduk N, Marion L. The effect of surface grinding and sandblasting on flexural strength and reliability of Y-TZP zirconia ceramic. Dent Mater 1999;15:426-33.

19. Wang H, Aboushelib MN, Feilzer AJ. Strength influencing variables on CAD/CAM zirconia frameworks. Dent Mater 2008;24:633-8.

20. Karakoca S, Yilmaz H. Influence of surface treatments on surface roughness, phase transformation, and biaxial flexural strength of Y-TZP ceramics. J Biomed Mater Res B Appl Biomater 2009;91:930-7.

21. Monaco C, Cardelli P, Scotti R, Valandro LF. Pilot evaluation of four experimental conditioning treatments to improve the bond strength between resin cement and Y-TZP ceramic. J Prosthodont 2011;20:97-100.

22. Ozcan M, Nijhuis H, Valandro LF. Effect of various surface conditioning methods on the adhesion of dual-cure resin cement with MDP functional monomer to zirconia after thermal aging. Dent Mater J 2008;27:99-104.

23. Phark JH, Duarte S Jr, Blatz M, Sadan A. An in vitro evaluation of the long-term resin bond to a new densely sintered high-purity zirconium-oxide ceramic surface. J Prosthet Dent 2009;101:29-38.

24. Zhang Y, Lawn BR, Rekow ED, Thompson VP. Effect of sandblasting on the long-term performance of dental ceramics. J Biomed Mater Res B Appl Biomater 2004;71:381-6.

25. Wimmer T, Erdelt KJ, Raith S, Schneider JM, Stawarczyk B, Beuer F. Effects of differing thickness and mechanical properties of cement on the stress levels and distributions in a three-unit zirconia fixed prosthesis by FEA. J Prosthodont 2014 Jan 13. doi: 10.1111/jopr.12125. [Epub ahead of print]

26. Guess PC, Zhang Y, Kim JW, Rekow ED, Thompson VP. Damage and reliability of Y-TZP after cementation surface treatment. J Dent Res 2010;89: 592-6.

27. Kelly JR, Giordano R, Pober R, Cima MJ. Fracture surface analysis of dental ceramics: clinically failed restorations. Int J Prosthodont 1990;3:430-40.

28. Guazzato M, Quach L, Albakry M, Swain MV. Influence of surface and heat treatments on the flexural strength of Y-TZP dental ceramic. J Dent 2005;33:9-18.

29. Ali AO, Kelly JR, Zandparsa R. The influence of 
different convergence angles and resin cements on the retention of zirconia copings. J Prosthodont 2012;21:614-21.

30. Ozcan M, Kerkdijk S, Valandro LF. Comparison of resin cement adhesion to Y-TZP ceramic following manufacturers' instructions of the cements only. Clin Oral Investig 2008;12:279-82.

31. Re D, Augusti D, Sailer I, Spreafico D, Cerutti A. The effect of surface treatment on the adhesion of resin cements to Y-TZP. Eur J Esthet Dent 2008;3: 186-96.

32. Chai J, Chu FC, Chow TW. Effect of surface treatment on shear bond strength of zirconia to human dentin. J Prosthodont 2011;20:173-9.

33. Attia A, Kern M. Effect of cleaning methods after reduced-pressure air abrasion on bonding to zirconia ceramic. J Adhes Dent. 2011;13:561-7.

34. Piascik JR. Critical appraisal. Resin bonding to zirconia. J Esthet Restor Dent 2012;24:417-20.

35. Liu D, Pow EH, Tsoi JK, Matinlinna JP. Evaluation of four surface coating treatments for resin to zirconia bonding. J Mech Behav Biomed Mater 2014; 32:300-9.
36. Abduo J, Lyons K, Swain M. Fit of zirconia fixed partial denture: a systematic review. J Oral Rehabil 2010;37:866-76.

37. Beuer F, Aggstaller H, Edelhoff D, Gernet W, Sorensen J. Marginal and internal fits of fixed dental prostheses zirconia retainers. Dent Mater 2009;25: 94-102.

38. May LG, Kelly JR, Bottino MA, Hill T. Effects of cement thickness and bonding on the failure loads of CAD/CAM ceramic crowns: multi-physics FEA modeling and monotonic testing. Dent Mater 2012; 28:e99-109.

39. Kohn DH. Acoustic emission and nondestructive evaluation of biomaterials and tissues. Crit Rev Biomed Eng 1995;23:221-306.

40. Zhang H, Li DY. Determination of interfacial bonding strength using a cantilever bending method with in situ monitoring acoustic emission. Surf Coat Technol 2002;155:190-4. 


\section{Y-TZP zirconia의 기계적 표면처리가 파절저항과 접착계면 실패에 미치는 영향}

\section{이양진*}

분당서울대병원 치과보철과

목적: 본 연구의 목적은 air-blasting particle size를 달리하고 분사 압력과 시간을 통상보다 크게 증가시켜 표면에 큰 손 상을 유발한 군을 상대적으로 작은 손상을 유발한 군과 비교하여 파절 저항과 접착 강도 차이를 보이는지 평가하는 데 있다.

연구 재료 및 방법: 지르코니아(LAVA $\left.{ }^{\mathrm{TM}}\right)$ 디스크 표면에 각각 $30 \mu \mathrm{m}$ - particle size (Cojet) 2.8 bar 15초, $110 \mu \mathrm{m}$ - (Rocatec) $2.8 \mathrm{bar} 15$ 초, $110 \mu \mathrm{m}$ - (Rocatec) $3.8 \mathrm{bar} 30$ 초로 조건을 달리하여 표면처리 후 각각 이축 굽힘하중 강도 실험과 접착 파절 하중 실험을 실행하였다. 접착은 상아질 유사 베이스에 $200 \mu \mathrm{m}$ 두께의 레진시멘트로 시행하여 인장력을 극 대화하였으며 음향방출(AE) 센서로 실패하중을 검출하였다.

결과: 이축 굽힘하중 강도, 접착 파절하중은 세 군간 서로 유의성 있는 차이를 보이지 않았다 $(P>0.05)$. 접착 시편의 균 열은 대부분 radial crack이었다.

결론: 정하중 평가의 한계 내에서, air-blasting particle size와 압력에 의한 표면 손상은 크지 않았으며, 접착 파절하중 평가는 표면 손상과 접착 강도를 동시에 평가할 수 있는 방법이라 여겨진다.

(구강회복응용과학지 2014;30(2): 102-11)

주요어: 강도; 음향방출; 이축 굽힘; 접착; 지르코니아; 에어블라스팅

*교신저자: 이양진

(463-707) 경기도 성남시 분당구 구미동 300 , 분당서울대학교병원 치과보철과

Tel: 031-787-7546 | Fax: 031-787-4068 | E-mail: navydent@snubh. org

접수일: 2014년 4월 29일 | 수정일: 2014년 5월 10일 | 채택일: 2014년 5월 17일 